\title{
Endodontic Perforation Closure by Five Mineral Oxides Silicate-Based Cement with/without Collagen Sponge Matrix
}

\author{
Talal Al-Nahlawi $\mathbb{D}^{1},{ }^{1}$ Maisour Ala Rachi, ${ }^{1}$ and Amjad Abu Hasna ${ }^{2}{ }^{2}$ \\ ${ }^{1}$ Operative Dentistry and Endodontics Department, Syrian Private University (S.P.U), Damascus, Syria \\ ${ }^{2}$ Department of Restorative Dentistry, Endodontics Division, Institute of Science and Technology, \\ São Paulo State University - UNESP, São José Dos Campos, São Paulo, Brazil \\ Correspondence should be addressed to Talal Al-Nahlawi; talal.alnahlawi@gmail.com
}

Received 30 May 2021; Accepted 26 August 2021; Published 8 September 2021

Academic Editor: Zohaib Khurshid

Copyright (c) 2021 Talal Al-Nahlawi et al. This is an open access article distributed under the Creative Commons Attribution License, which permits unrestricted use, distribution, and reproduction in any medium, provided the original work is properly cited.

\begin{abstract}
Endodontic perforations are common accidents that occasionally happen as a result of misuse or difficult anatomy of some teeth; it may lead to teeth loss unless a good management is provided. Bioceramic (silicate-based) cements like mineral trioxide aggregate have a big role in management of such accidents. This case report aimed to evaluate the ability of five mineral oxides cement " $5 \mathrm{MO}$ " in sealing two root canal perforations (furcation and postdrill perforations) and inducing clinical and radiographic healing in the periodontal tissues with/without the use of collagen sponge matrix. A 58-year-old healthy female was referred to our dental office complaining of severe pain in the upper left premolars' region. Periapical radiographic examination revealed unsatisfactory root canal treatment of the teeth \#24 and \#25 with a furcation perforation and a postdrill perforation, respectively. Cone-beam computed tomography "СBCT" scans confirmed the findings of the periapical radiography and revealed the presence of radiolucent lesions surrounding the apex of both teeth \#24 and \#25. The treatment plan was a nonsurgical root canal retreatment by endodontic access through the full-ceramic crowns. After three years of follow-up, CBCT scans revealed a complete healing and bone formation on both premolars. This case report indicates the use of $5 \mathrm{MO}$ cement for endodontic perforations management.
\end{abstract}

\section{Introduction}

Endodontic perforation is defined as the communication of the root canal system with the periodontium, it is considered as an accident of the root canal treatment "RCT," and it may lead to tooth loss unless a good management is provided $[1,2]$. Conversely, it results from noniatrogenic factors like progressive internal resorption or active caries lesion [3].

Regeneration in endodontics started in the last century, with some attempts by researchers, to induce regeneration and repair of exposed cavities $[4,5]$. Calcium hydroxide " $\mathrm{Ca}(\mathrm{OH})_{2}$," beside others, was the material of choice for tissue regeneration and repair [6], until the mineral trioxide aggregates "MTA" release at the end of the twentieth century as the first biocompatible and reparative silicate-based cement [7]. MTA is an effective material in sealing of lateral and furcation perforations $[7,8]$, and it can be applied using both immediate and mediate techniques [9]. Furthermore, it is indicated for apexogenesis, apexification, and revascularization of vital and nonvital immature teeth [10-12]. Later, several bioceramic (silicate-based) cements of the same chemical formula were released [13, 14].

Five mineral oxides " $5 \mathrm{MO}$ " is a new repair silicate-based cement, derived from Portland cement, developed to treat all endodontic complications and accidents (patent). As a capping material, it is effective as $\mathrm{Ca}(\mathrm{OH})_{2}$ (Dycal) [15] and MTA [16] and as a root-end filling material in apicoectomy $[17,18]$.

Collagen sponge is a biodegradable material, indicated as a surgical tampon [19]. In some endodontic perforations, it may be indicated as a matrix for the repair cement insertion [20] as it does not interfere in the healing process [21].

The aim of this case report was to evaluate the ability of $5 \mathrm{MO}$ in sealing two root canal perforations (furcation and 
postdrill perforations) and inducing clinical and radiographic healing in the periodontal tissues with/without the use of collagen sponge.

\section{Case Report}

2.1. Case History. A 58-year-old healthy female was referred to our dental office complaining of severe pain in the upper left premolars' region with no history of trauma. However, the patient related a previous root canal treatment of most of her upper teeth, including the premolars, as a demand for "Hollywood smile," according to the indication of the anterior professionals in the past six months, even without a pathological indication.

2.2. Patient Assessment. The clinical investigation revealed severe pain (positive response) to vertical percussion and digital palpation in the periapical region of tooth \#24. However, the neighboring teeth \#23 and \#25 presented negative responses for the same exams. There was no fistula nor swelling related to the evaluated teeth. The crowns were well-adapted without any infiltration, and the periodontal exploration revealed gingival pocket varied between 1 and $3 \mathrm{~mm}$ with various exploring locations and grade I mobility. Teeth \#23-25 were tested by the pulp vitality test (the cold test) as detailed in a previous study [22]. Teeth \#24 and \#25 presented negative responses; conversely, tooth \#23 was vital with characteristics of healthy pulp.

Periapical radiographic examination revealed unsatisfactory root canal treatment of the tooth \#24 presenting: (I) missed lingual canal; (II) furcation perforation (obturated and condensed with gutta-percha); (III) susceptible broken instrument in the furcation area; and (IV) broken instrument in the apical third of buccal canal. The remaining part of the buccal canal was obturated with gutta-percha, and a fiber post was inserted in the coronal part; then, the tooth was crowned.

In addition to an unsatisfactory root canal treatment of the tooth \#25 is associated with a lateral lesion because of postdrill perforation. Cone-beam computed tomography "CBCT" scans confirmed the findings of the periapical radiography and revealed the presence of radiolucent lesions surrounding the apex of both teeth \#24 and \#25 (Figure 1).

The final diagnosis was acute periapical periodontitis of tooth \#24 and chronic periapical periodontitis of tooth \#25. The treatment plan was a nonsurgical root canal retreatment by endodontic access through the full-ceramic crowns with final composite resin restoration for teeth \#24 and \#25. An informed consent form was signed by the patient agreeing to undergo the treatment plan and authorizing the publication of the case report.

\subsection{Clinical Interventions}

2.3.1. Tooth \#24. After rubber dam isolation and under microscopic magnification by SmartOptic dental microscope (Diplomat Dental, Piestany Slovakia), the access cavity was performed through the full-ceramic crown using a straight fissure diamond bur until $5 \mathrm{~mm}$ of depth and before reaching the furcation area (Figure 2(a)). Then, Start-X \#5 ultrasonic tip (Dentsply Sirona, São Paulo, SP, Brazil) was used to remove the composite resin restoration covering the furcation perforation using the P5 NEWTRON ultrasound activator (Acteon, Indaiatuba, SP, Brazil) at 6-frequency (Endo function). Once the perforation was uncovered, a considerable amount of bleeding came out (Figure 2(b)).

After bleeding control and perforation site evaluation $(3 \times 3 \mathrm{~mm})$, the lingual canal was detected and scouted using K-file \#10 (Dentsply, Petropolis, RJ, Brazil) (Figure 2(c)). Periapical radiography confirmed the detection of the lingual canal (Figure 2(g)). Disinfection of the perforation site was done using sodium hypochlorite "NaOCl" $1 \%$. The site was dried by cotton pellet, and $\mathrm{Ca}(\mathrm{OH})_{2}$ powder (Sultan HealthCare, York, PA, USA) was mixed with sterile saline solution and applied over the perforation site. The tooth was restored by temporary filing of Coltosol (Coltene, Rio de Janeiro, RJ, Brazil) and sealed by a layer of glass ionomer cement (Ivoclar Vivadent Ltda, Barueri, SP, Brazil) for 14 days.

In the second session, the pain was completely controlled. The temporary filling was removed, and the $\mathrm{Ca}(\mathrm{OH})_{2}$ dressing was washed away using sterile saline solution irrigation; then, the Zumax micro tweezer (Zumax medical, Suzhou New District, China) was used to catch and remove the obturation material (gutta-percha) from the perforation site (Figure 2(d)). Then, ultrasonic irrigation was performed using U-file (NSK, Suzano, SP, Brazil) at 2-frequency (Endo function) and sterile saline solution to remove any remaining materials from the furcation perforation including the susceptible broken file inside the furcation perforation.

Periapical radiography confirmed the removal of all foreign bodies from furcation perforation (Figure 2(h)). Then, a collagen sponge was packed inside the furcation perforation to form a matrix (Figure 2(e)), and the 5MO silicate-based cement (Golden Yatti LLC Muscat, Oman) was applied using the microapical placement system "MAP" (Dentsply Tulsa, Switzerland) over the collagen matrix to seal the large perforation site (Figure 2(f)). A wet cotton pellet was applied over the $5 \mathrm{MO}$ to accelerate the complete setting of the material, paying attention to keep the lingual canal entrance free. Last, the $5 \mathrm{MO}$ was sealed with glass ionomer cement (Ivoclar Vivadent Ltda, Barueri, SP, Brazil).

Then, the fiber post in the buccal canal was removed by penetrating and enlarging the fiber post from inside using LN bur size 0.6 (Dentsply Maillefre, São Paulo, SP, Brazil) and Pesso reamers files sizes 1-3 (Dentsply Maillefre, São Paulo, SP, Brazil); then, the remaining part of the fiber post was drilled away using ultrasonic tip ET20 (Acteon, Indaiatuba, SP, Brazil) till the pink color of the gutta-percha appeared.

The obturating material was removed using D3 retreatment rotary file (Dentsply Maillefer, São Paulo, SP, Brazil) at a $300 \mathrm{rpm}$ rotation speed associated with $\mathrm{NaOCl}$ $5.25 \%$ irrigation (Figure 2(i)). The apical broken file was bypassed using manual K-files sizes \#6, 8, and 10. Then, buccal and lingual canals were instrumented with rotary files 

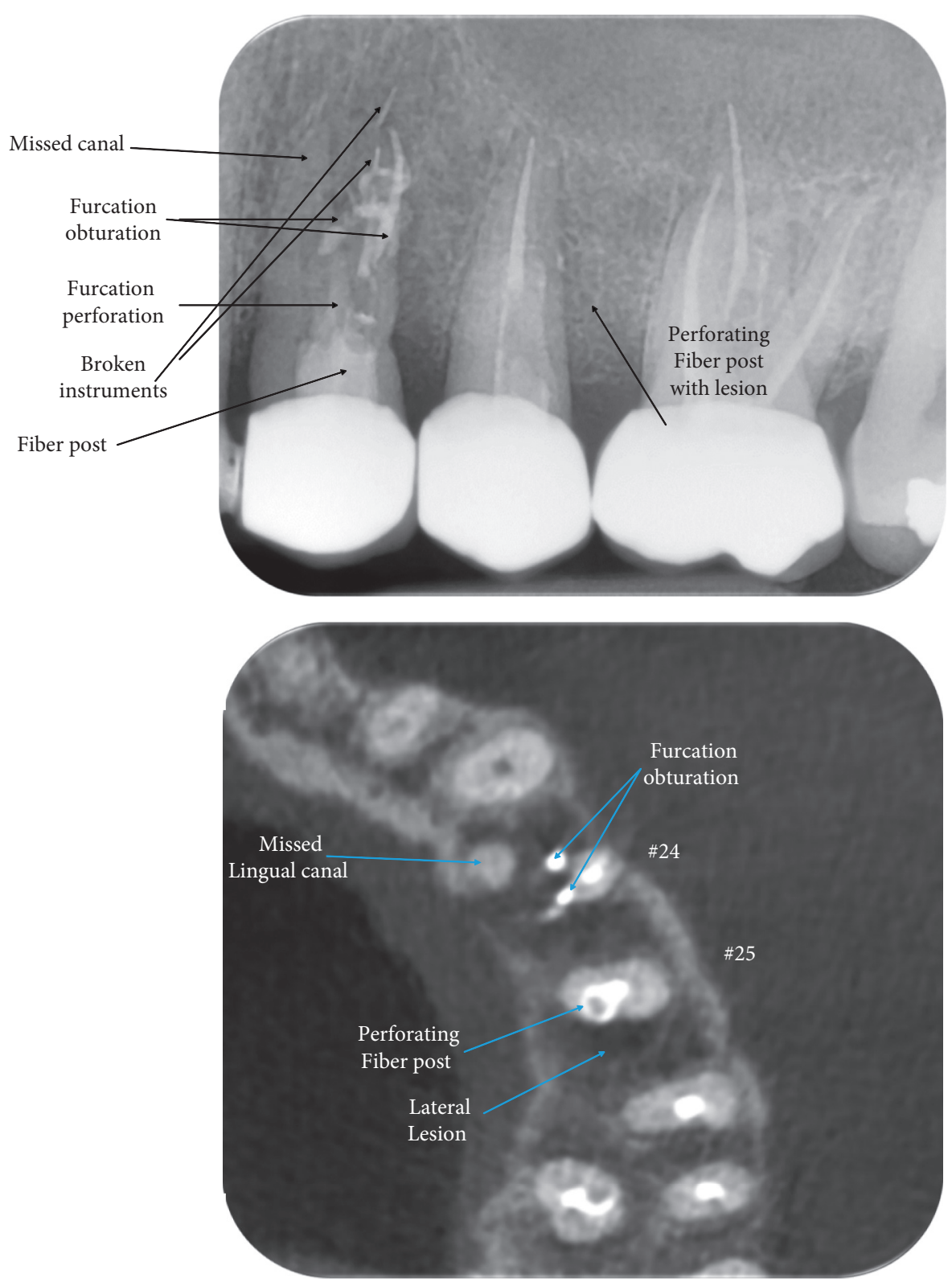

FIgURE 1: The initial periapical radiography and the axial section of CBCT scans of the teeth \#24 and \#25.

Revo S rotary systems 25.06 (MicroMega, Besancon, France). Ultrasonic irrigation was performed using U-file at 2 -frequency (Endo function) and $\mathrm{NaOCl} 5.25 \%$. Then, the canals were dried with paper points 25.06 (Dentsply Maillefer, São Paulo, SP, Brazil) and obturated using the single cone technique with a 25.06 gutta-percha cone (Dentsply Maillefer, São Paulo, SP, Brazil) and bioceramic sealer (CeraSeal, Meta Biomed, Colmar, PA, USA) (Figure 2(j)).

2.3.2. Tooth \#25. Again, the same steps were followed, until reaching the fiber post (Figure 3(a)); however, while removing it with the ultrasonic tip ET20, the fiber post was pushed out into the drill post (lateral) perforation because the fiber postpreparation extends out of the root canal in a distal direction (Figure 3(d)). Later, the fiber post was removed (Figure 3(b)) using a long and narrow endo probe with the aid of ultrasonic tip ET25 (Acteon, Indaiatuba, SP, Brazil) associated with copious irrigation of the perforation site. $\mathrm{Ca}(\mathrm{OH})_{2}$ dressing was also applied over the perforation site till the next session.

The perforation site, measuring around $3 \times 3 \mathrm{~mm}$, was sealed using $5 \mathrm{MO}$ silicate-based cement (Figure 3(c)), without a collagen sponge application. The cement did not overextrude, and this was confirmed radiographically (Figure 3(e)). The same steps were followed again for retreating and obturating the single root canal of tooth \#25 (Figure 3(f)). Both teeth were restored with composite resin restoration (3M ESPE, Seefeld, Germany) after a base of glass ionomer cement.

2.4. Follow-Up and Outcomes. One month later, the patient had no postoperative complications, and an intraoral evaluation was performed to investigate any swelling, 


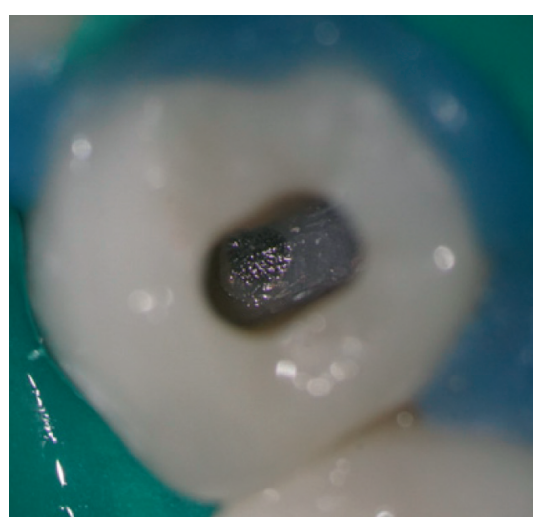

(a)

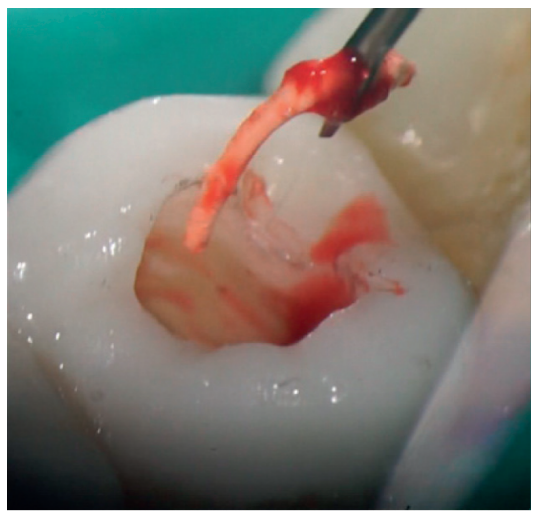

(d)

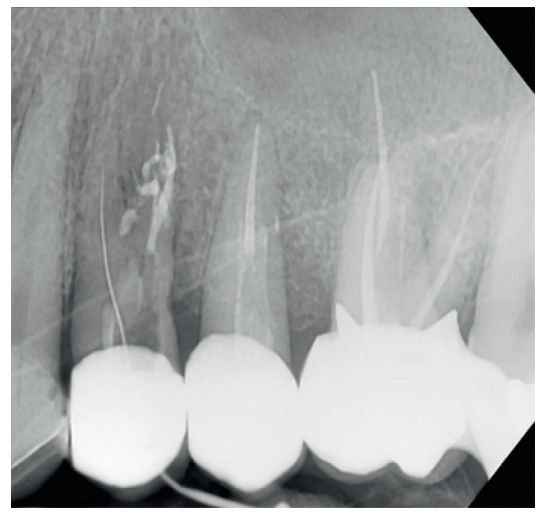

(g)

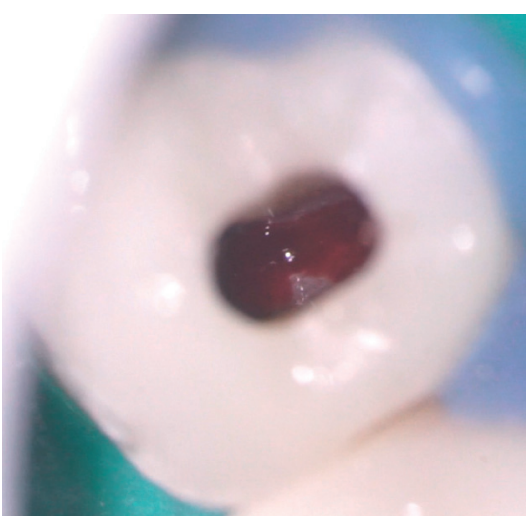

(b)

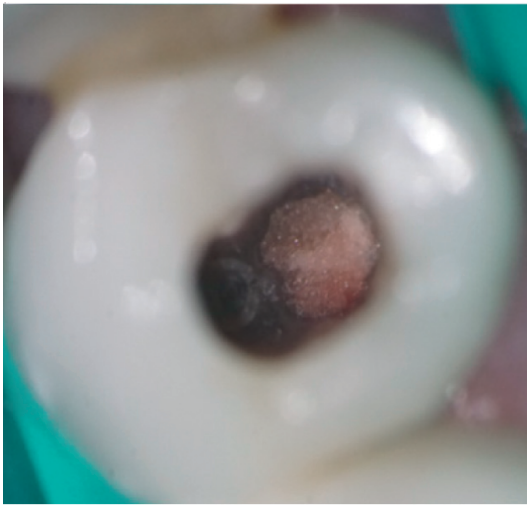

(e)

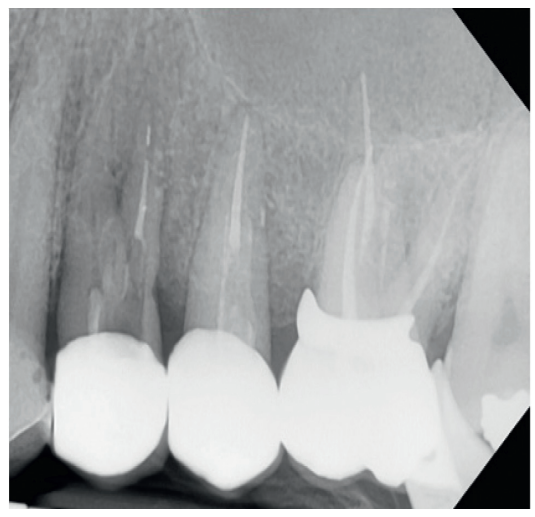

(h)

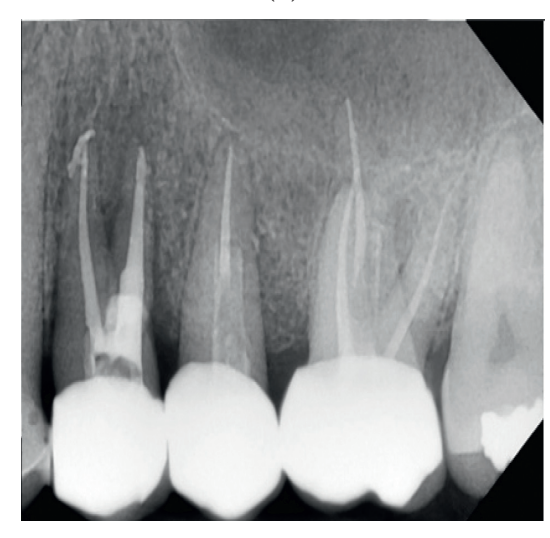

(j)

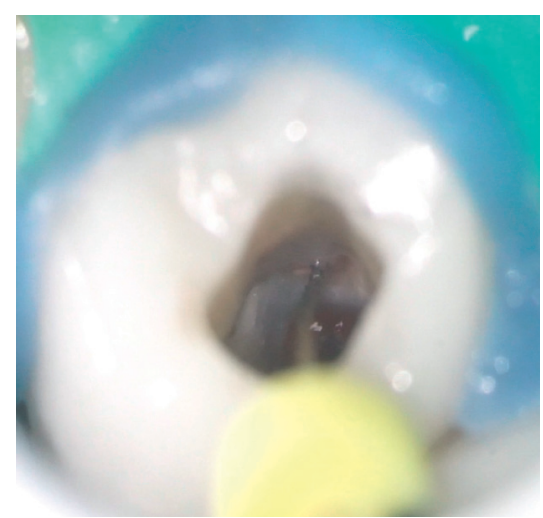

(c)

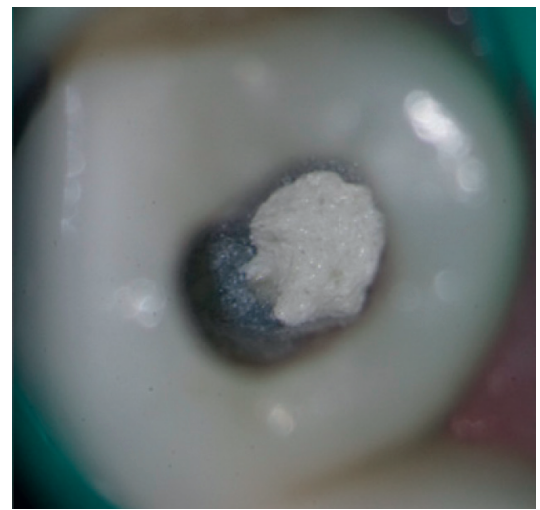

(f)

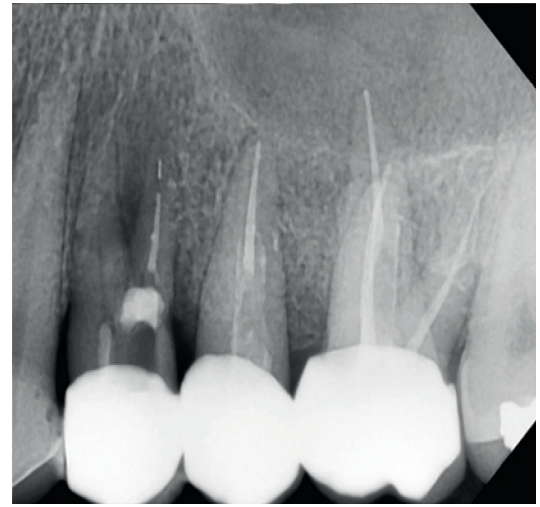

(i) 


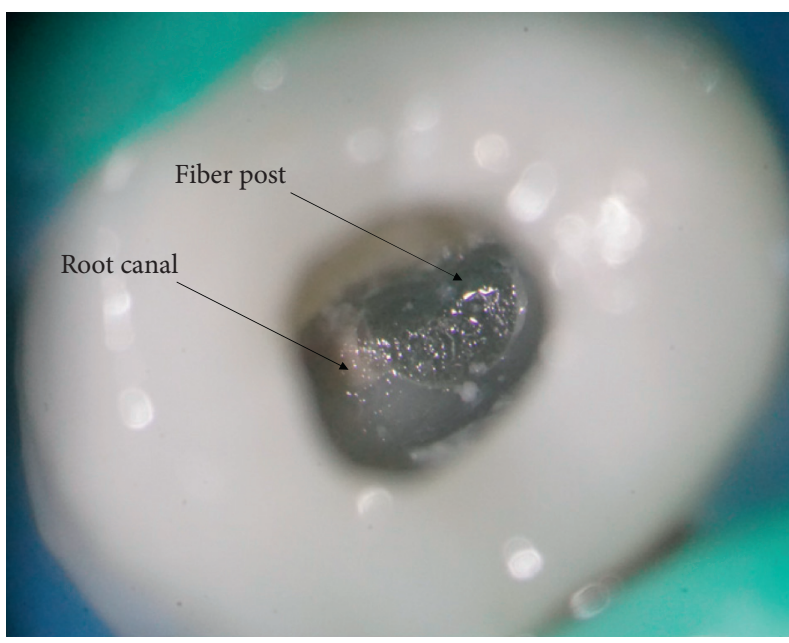

(a)

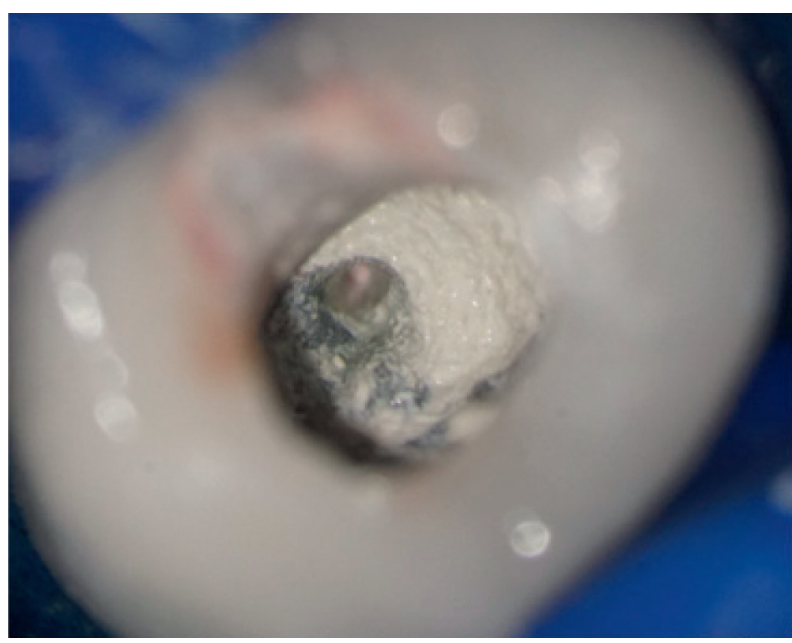

(c)

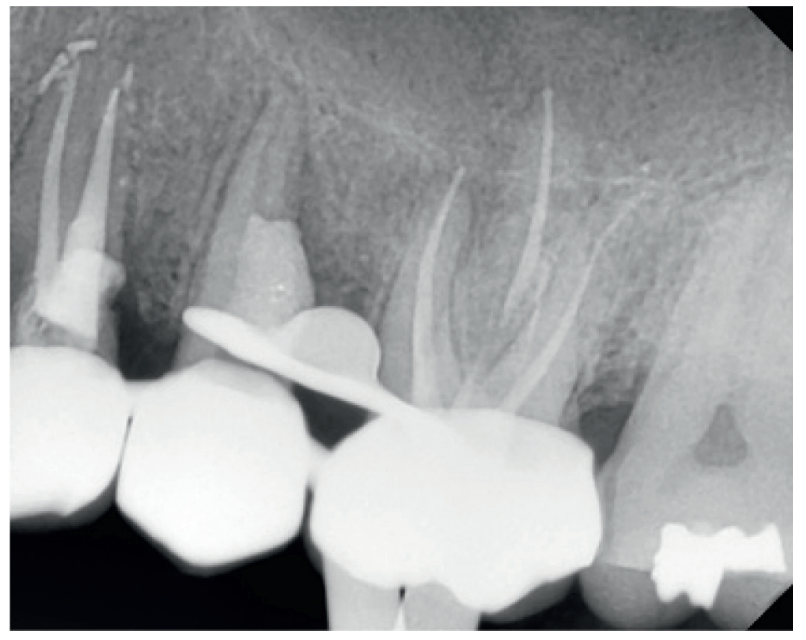

(e)

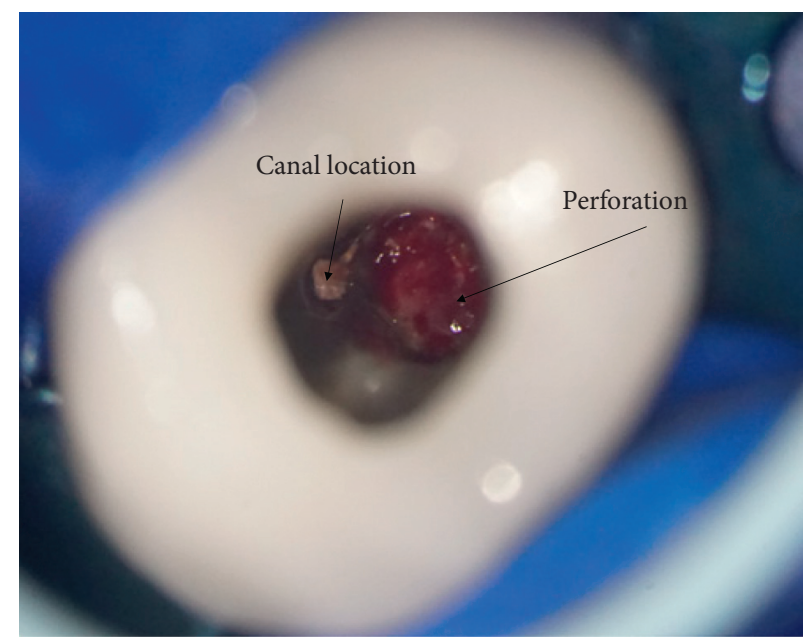

(b)

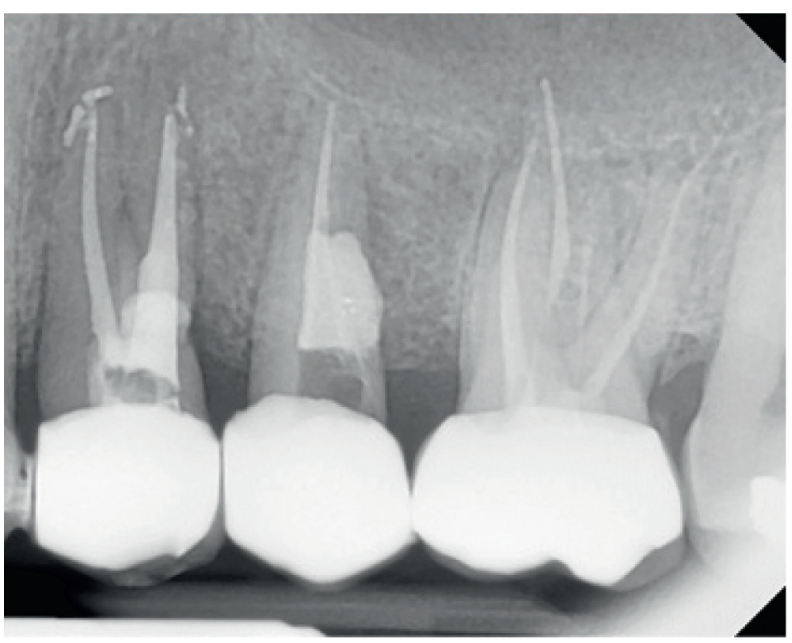

(d)

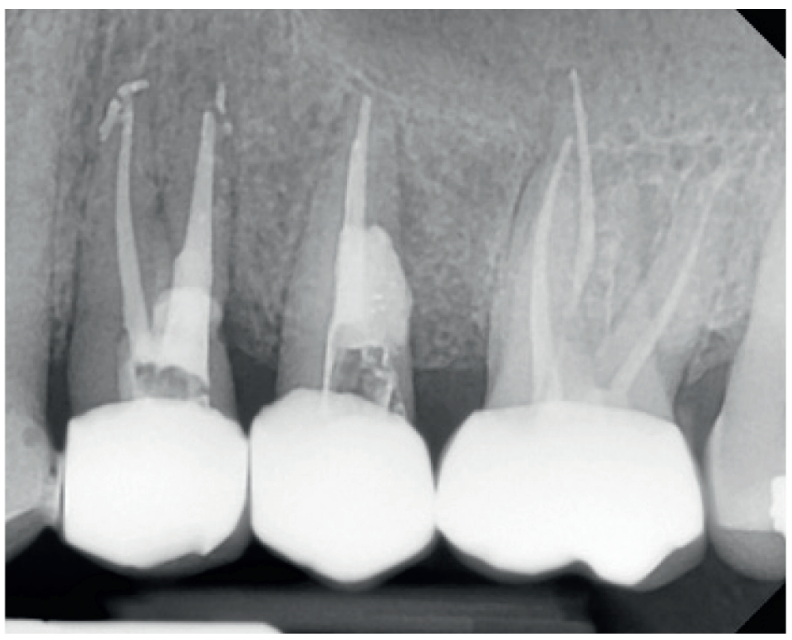

(f)

Figure 3: Clinical images and periapical radiographs of the retreatment of tooth \#25. (a) Access cavity; (b) bleeding perforation; (c) 5MO cement application; (d) radiography of 5MO cement application; (e) radiography of cleaned and prepared canal; and (f) radiography of obturation. 

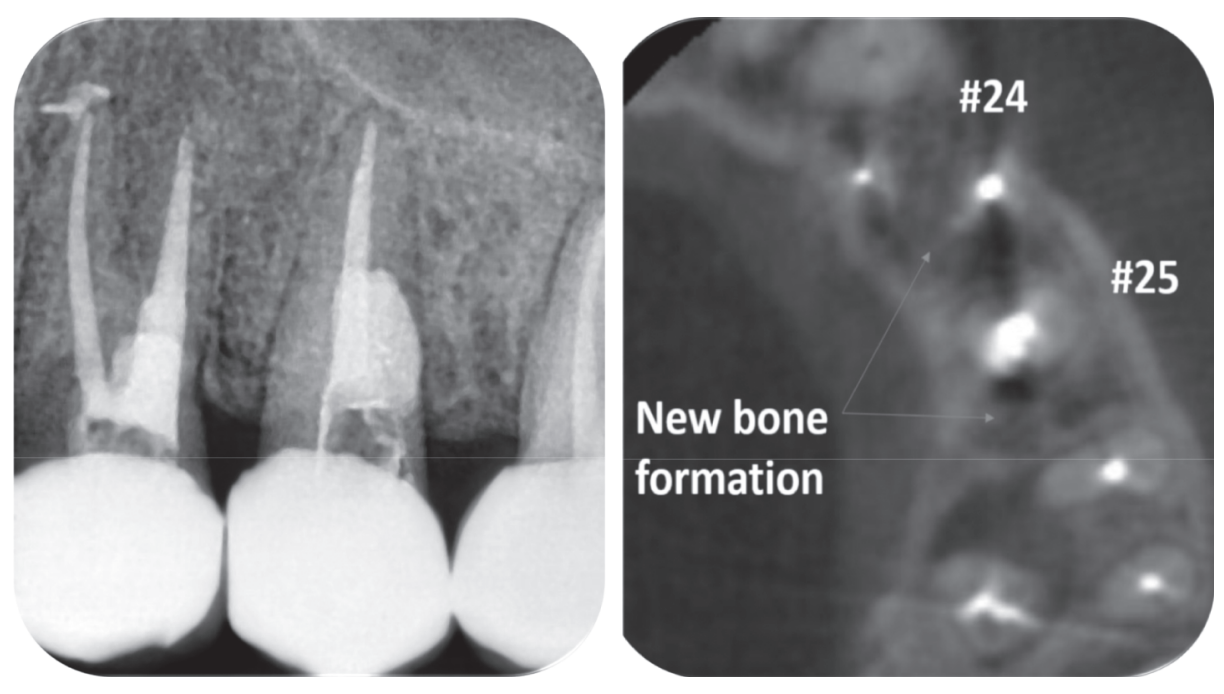

FIgUre 4: Periapical radiography and CBCT image after a 3-year follow-up.

edema, or fistula. The patient related comfort and satisfaction with the treatment.

Three years later, another follow-up session was performed. The clinical intraoral examination revealed a well-adapted full-ceramic crown, without signs of caries or marginal infiltration. Radiographically, healed periapical and lateral lesions were noticed, and a bone neoformation was observed (Figure 4(a)). Last, the CBCT scans presented complete healing and bone formation on both premolars. The patient was advised to retreat the upper adjacent molar as a radiolucent lesion was detected (Figure 4(b)).

\section{Discussion}

The adequate treatment planning demands an accurate diagnosis [23]; for this, CBCT scans were used in this case report due to its high resolution and its effectivity in determining the relationship between the root apexes and the adjacent anatomical structures [24], beside its capacity to localize the perforations' sites. In this case report, both furcation and postdrill perforations were closed by $5 \mathrm{MO}$ silicate-based cement using the mediate technique because of the presence of lesions associated to these perforations. The proposal was that $\mathrm{Ca}(\mathrm{OH})_{2}$ dressing will disinfect, dry the exudate, and elevate the $\mathrm{pH}$ at the perforation site before sealing with bioactive material [25]. MTA has presented good results in both immediate and mediate techniques [9]. Therefore, 5MO silicate-based cement should be evaluated in both techniques.

The silicate-based cement sealing should be associated with root canal disinfection to guarantee the success of the root canal treatment in perforated [26] or immature teeth [18]. MTA presented a satisfactory antibacterial effect over some facultative bacteria, but no effect over strict anaerobic bacteria [27]. This antimicrobial action is explained by the alkaline $\mathrm{pH}$ of bioceramic or silicate-based cements that tends to increase over time [28]. However, the 5MO antimicrobial action was not studied yet. Therefore, it indicated the use of antimicrobial agents in this study.

It was stated in the literature that the adequate disinfection of the root canal system and the sealing site, associated with the sealing ability of $5 \mathrm{MO}$ bioceramic cement results in satisfactory clinical and radiographic healing [18]. This disinfection was achieved in the current case report by the antimicrobial action of sodium hypochlorite as endodontic irrigant $[29,30]$ and calcium hydroxide as a dressing [31]. Ultrasonic activation was used to improve the endodontic irrigant penetration [30].

Other factors play a major role in healing, and preventing the lesion progression is the matrix metalloproteinases deactivation and endotoxins (LPS and LTA) detoxification, and this may be achieved by the irrigation of the root canal system by sodium hypochlorite [30, 32], besides the sealing ability of the $5 \mathrm{MO}$ cement [18] and the good biocompatibility, osteoconductivity, and osteoinductivity of silicate-based cements [33].

In this case report, the furcation perforation was managed using collagen sponge to serve as a matrix to prevent $5 \mathrm{MO}$ silicate-based cement extrusion [34]. Conversely, in the postdrill perforation, there was no need to use a collagen sponge as the perforation was lateral, and the condensation forces were applied gently with large cut paper point in apical direction, in addition to the presence of inflammatory lateral tissues that served as a matrix [35].

$5 \mathrm{MO}$ was the material of choice in this case report because of its sealing ability stated previously $[15,17,18]$; therefore, $5 \mathrm{MO}$ can be used as an effective silicate-based cement in perforations management; however, more case reports and clinical studies should be realized to evaluate its cytotoxicity and tissue repair ability for long periods.

\section{Conclusion}

It was concluded that $5 \mathrm{MO}$ is considered as effective silicatebased cement in furcation and postdrill perforations closure with and without a collagen matrix. 


\section{Data Availability}

No data were used to support the findings of this study.

\section{Conflicts of Interest}

The author Maisour Ala Rachi has a patent of five mineral oxides cement. The other authors declare that they have no conflicts of interest.

\section{Acknowledgments}

The authors wish to thank the Syrian Private University "S.P.U" for all their unconditional support in writing this case report.

\section{References}

[1] P. Singh, J. Paul, A. A. Al-Khuraif et al., "Sealing ability of mineral trioxide aggregate, calcium phosphate cement, and glass ionomer cement in the repair of furcation perforations," Acta Medica (Hradec Kralove, Czech Republic), vol. 56, no. 3, pp. 97-103, 2013.

[2] T. R. Pitt Ford, M. Torabinejad, D. J. McKendry, C.-U. Hong, and S. P. Kariyawasam, "Use of mineral trioxide aggregate for repair of furcal perforations," Oral Surgery, Oral Medicine, Oral Pathology, Oral Radiology \& Endodontics, vol. 79, no. 6, pp. 756-763, 1995

[3] J. Mente, N. Hage, T. Pfefferle et al., "Treatment outcome of mineral trioxide aggregate: repair of root perforations," Journal of Endodontics, vol. 36, no. 2, pp. 208-213, 2010.

[4] Macler, "The regeneration of pulpal wall bacteriostatic treatment]," Rev. Odontol. Parana.vol. 69, no. 12, pp. 574-588, 1947.

[5] A. P Lund, "Healing of exposures in caries exposed pulps," Journal of Dental Research, vol. 26, no. 6, p. 464, 1947.

[6] M. Cvek, "Treatment of non-vital permanent incisors with calcium hydroxide. I. Follow-up of periapical repair and apical closure of immature roots," Odontologisk Revy, vol. 23, no. 1, pp. 27-44, 1972.

[7] S.-J. Lee, M. Monsef, and M. Torabinejad, "Sealing ability of a mineral trioxide aggregate for repair of lateral root perforations," Journal of Endodontics, vol. 19, no. 11, pp. 541-544, 1993.

[8] R. S. Alsulaimani, "Immediate and delayed repair of 2 sizes of furcal perforations in dogs' teeth using mineral trioxide aggregate cement," Journal of Endodontics, vol. 44, no. 6, pp. 1000-1006, 2018.

[9] N. C. T. Marques, N. Lourenço Neto, and T. M. Oliveira, "Immediate and mediate furcal perforation treatment in primary molars: 24-month follow-up," European Archives of Paediatric Dentistry, vol. 17, no. 6, pp. 489-494, 2016.

[10] P. Linsuwanont, S. Kulvitit, and B. Santiwong, "Reinforcement of simulated immature permanent teeth after mineral trioxide aggregate apexification," Journal of Endodontics, vol. 44, no. 1, pp. 163-167, 2018.

[11] S. R. Kvinnsland, A. BÃ¥rdsen, and I. Fristad, “Apexogenesis after initial root canal treatment of an immature maxillary incisor â a case report," International Endodontic Journal, vol. 43, no. 1, pp. 76-83, 2010.

[12] K. Saeki, Y. Fujita, Y. Shiono, Y. Morimoto, and K. Maki, "Pulp revascularization in immature permanent tooth with apical periodontitis using mineral trioxide aggregate," Case reports in medicine, vol. 2014, p. 564908, 2014.

[13] A. Flores-Ledesma, F. Barceló Santana, L. Bucio, J. A. ArenasAlatorre, M. Faraji, and A. M. Wintergerst, "Bioactive materials improve some physical properties of a MTA-like cement," Materials Science and Engineering: C, vol. 71, pp. 150-155, 2017.

[14] A. Ghorbanzadeh, N. Shokouhinejad, B. Fathi, M. Raoof, and M. Khoshkhounejad, "An in vitro comparison of marginal adaptation of MTA and MTA-like materials in the presence of PBS at one-week and two-month intervals," Journal of Dentistry (Tehran, Iran), vol. 11, no. 5, pp. 560-568, 2014.

[15] M. N. A. Rachi, T. F. Al-Nahlawi, and M. T. Kouki, "New five minerals oxides pulp capping material compared with dycal," Dental Materials, vol. 30, p. e126, 2014.

[16] F. Darweesh, t. shahawy, N. Zaghloul, and M. Almowaqee, "Impact of a new silicate-based capping material on healing potentiality of traumatically exposed healthy dog's dental pulp," Egyptian Dental Journal, vol. 66, no. 2, pp. 981-989, 2020.

[17] E. I. Flores Orozco, A. Abu Hasna, M. Teotonio de Santos Junior et al., "Case Report: interdisciplinary management of a complex odontoma with a periapical involvement of superior anterior teeth," F1000Research, vol. 8, p. 1531, 2019.

[18] A. Abu Hasna, D. Pereira Santos, T. R. Gavlik de Oliveira, A. B. A. Pinto, C. R. Pucci, and J. L. Lage-Marques, "Apicoectomy of perforated root canal using bioceramic cement and photodynamic therapy," International Journal of Dentistry, vol. 20208 pages, 2020.

[19] M. Chvapil, "Collagen sponge: theory and practice of medical applications," Journal of Biomedical Materials Research, vol. 11, no. 5, pp. 721-741, 1977.

[20] D. V. Tsatsas, H. A. Meliou, and N. P. Kerezoudis, "Sealing effectiveness of materials used in furcation perforation in vitro," International Dental Journal, vol. 55, no. 3, pp. 133-141, 2005.

[21] Y. Jang, H. Kim, B.-D. Roh, and E. Kim, "Biologic response of local hemostatic agents used in endodontic microsurgery," Restorative Dentistry \& Endodontics, vol. 39, no. 2, pp. 79-88, 2014.

[22] A. Abu Hasna, C. H. Ferrari, and C. A. Talge Carvalho, "Endodontic treatment of a large periapical cyst with the aid of antimicrobial photodynamic therapy - case report," Brazilian Dental Science, vol. 22, no. 4, pp. 561-568, 2019.

[23] A. Abu Hasna, "Pictograph system for diagnosis making and data management in endodontics," Brazilian Dental Science, vol. 23 , no. $4,2020$.

[24] C. H. Ferrari, A. Abu Hasna, and F. C. Martinho, "Three Dimensional mapping of the root apex: distances between apexes and anatomical structures and external cortical plates," Brazilian Oral Research, vol. 35, Article ID e022, 2021.

[25] S. Best, C. L. Ammons, G. A. Karunanayake, S. R. Saemundsson, and P. Z. Tawil, "Outcome assessment of teeth with necrotic pulps and apical periodontitis treated with long-term calcium hydroxide," Journal of Endodontics, vol. 47, no. 1, pp. 11-18, 2021.

[26] C. Estrela, D. A Decurcio, G Rossi-Fedele, J. A Silva, O. A Guedes, and ÁH Borges, "Root perforations: a review of diagnosis, prognosis and materials," Brazilian Oral Research, vol. 32, no. suppl 1, p. e73, 2018.

[27] M. Torabinejad, C. U. Hong, T. R. P. Ford, and J. D. Kettering, "Antibacterial effects of some root end filling materials," Journal of Endodontics, vol. 21, no. 8, pp. 403-406, 1995. 
[28] M. S. Zafar, A. A. Alnazzawi, M. Alrahabi, M. A. Fareed, S. Najeeb, and Z. Khurshid, Nanotechnology and Nanomaterials in Dentistry//Advanced Dental Biomaterials, Elsevier, Amsterdam, Netherland, 2019.

[29] J. F. Siqueira, I. N. Rôças, A. Favieri, and K. C. Lima, "Chemomechanical reduction of the bacterial population in the root canal after instrumentation and irrigation with $1 \%$, $2.5 \%$, and $5.25 \%$ sodium hypochlorite," Journal of Endodontics, vol. 26, no. 6, pp. 331-334, 2000.

[30] A. Abu Hasna, L. Pereira Da Silva, F. C. Pelegrini, C. L. R. Ferreira, L. D. de Oliveira, and C. A. T. Carvalho, "Effect of sodium hypochlorite solution and gel with/without passive ultrasonic irrigation on Enterococcus faecalis, Escherichia coli and their endotoxins," F1000 Research, vol. 9, p. 642, 2020.

[31] A. Abu Hasna, "In vitro evaluation of the antimicrobial effect of $\mathrm{N}$-acetylcysteine and photodynamic therapy on root canals infected with Enterococcus faecalis//Iranian endodontic journal," 2020.

[32] C. A. T. Carvalho, A. A. Hasna, A. S. Carvalho et al., "Clinical study of sodium hypochlorite, polymyxin B and limewater effect on MMP-3,-8,-9 in apical periodontitis," Brazilian Dental Journal, vol. 31, no. 2, pp. 116-121, 2020.

[33] M. S. Zafar, F. Amin, M. A. Fareed et al., "Biomimetic aspects of restorative dentistry biomaterials," Biomimetics, vol. 5, no. 3, 2020.

[34] M. Graziele Magro, "Endodontic management of open apex teeth using lyophilized collagen sponge and MTA cement: report of two cases," Iranian Endodontic Journal, vol. 12, no. 2, pp. 248-252, 2017.

[35] H. Bakhtiar, H. Mirzaei, M. R. Bagheri et al., "Histologic tissue response to furcation perforation repair using mineral trioxide aggregate or dental pulp stem cells loaded onto treated dentin matrix or tricalcium phosphate," Clinical Oral Investigations, vol. 21, no. 5, pp. 1579-1588, 2017. 